some extraordinary way, to have avoided this racial admixture with Australians during their occupation of Australia. The second, that the influx of Negritos into Australia was an event altogether separate from their advent into Tasmania: that there were two independent Negrito migrations, one into the mainland that merged its blood with that of the Australians, the other into Tasmania direct and not via continental Australia and so preserving their full Negrito characters. It cannot be claimed that either of these hypotheses tends to clarify the question of the peopling of the Southern Continent.

Concerning the palate, Dr. Adam concludes that "it is more Tasmanoid than Australoid" in certain features. One of these features is that "it is relatively broad like the Tasmanian palate; the Australian palate is relatively narrower". It is unfortunate that of the Tasmanian and Australian palates figured in Plate XI, that of the Australian would seem to be of a considerably higher relative broadness.

The question would seem to arise as to the possibility of any physical anthropologist sorting out the constituent racial elements present in any individual skull. Tables of figures of comparative measurements are impressive; but it would seem that they are incapable of solving the problem. Taking Dr. Wunderly's tables 1 and 2, in which he gives measurements for Australian, Tasmanian, Maori, Marquesan and Hawaiian skulls, it is at once apparent that it cannot be from these that he has drawn the conclusion that the Keilor skull is compounded of Australoid and Tasmanoid characteristics in about equal proportions. If the measurements of the Keilor skull are matched with the measurements given in the tables of the other skulls, it will be found that in fifty-seven instances they come nearest to those of Australians, in thirty to those of Maoris, in twenty. nine to those of Marquesans, in twenty-one to those of Tasmanians and in eighteen to those of Hawaiians. Surely this is a very disconcerting result to be achieved by the refinements of craniometry. On the other hand, it can scarcely have been on the anatomical features of the skull that Dr. Wunderly makes such a very definite statement, for the morphological characters referred to in the communication are quite insufficient for arriving at a dogmatic diagnosis of racial mixture between the Pleistocene ancestors of the present Australian and Tasmanian races. It might be considered among the triumphs of craniology to diagnose with certainty the product of racial mixture between the Australian and the Tasmanian of the historic period. It is a bold claim indeed to be able to recognize an isolated cranium of an individual as being the product of the racial mixture between the Pleistocene ancestors of these two races living (according to the geological report) more than 100,000 years ago.

It is probably the assertions of Wunderly and Adam that have led Mr. Mahony to include the sentence, "The Keilor skull, which combines Tasmanian with Australian characteristics, supports the theory that Tasmanians once occupied the Australian mainland", in his admirable survey of the whole question of the antiquity of man in Australia. From Australia it is postulated that the Tasmanians passed by way of the Bass Straits Islands into Tasmania. Perhaps, therefore, it would be well to point out that, altogether apart from the question of race mixture already mentioned, there are several other difficulties in the way of accepting this hypothesis. If Tasmanians and Australians had inhabited continental
Australia side by side and had fused their races in Pleistocene times, it must be explained how it came about that the Tasmanian when first encountered by the white man had no dog, although the Australian had, even at the dawn of his story, dogs in plenty, for fossil dingo bones occur in Australia. No remains of the dingo, living or fossil, have ever been found in Tasmania or in the Bass Straits Islands; yet it is a historic fact that the Tasmanians eagerly seized on the cur dogs of the white man to assist them in their food quest. How came it that the Tasmanians remained ignorant of such familiar and important cul. tural developments as the use of the throwing stick, the stone-pointed spear, the boomerang and the shield, familiar enough and of widespread use in Australia?

The National Museum and its director are to be congratulated on having placed on record the first really well-authenticated example of human remains, assignable to a definite geological horizon, that has so far been brought to light in Australia. Here we have a genuine human document of first-class importance. The skull is safe in the custody of the National Museum, and it is much to be hoped that all the other human fragments will be placed in its permanent collections. There will be many opportunities for further examinations of the skeletal remains by anthropologists, and meanwhile it would perhaps be better to accept them as permanent documents rather than to assume that the conclusions drawn from their first examination are necessarily the final ones.

\section{COMPETITIVE RUBBER PLANTS*}

\author{
BY G. MARTIN
}

Superintendent of Research, London Advisory Committee for Rubber Research (Ceylon and Malaya)

GAR more plants contain rubber than is generally 4 realized, but. few contain enough to make extraction worth while. For example, the dandelion (Taraxacum officinale) is typical of the plants in Great Britain which, on bruising, yield a latex or milky fluid containing rubber; but the milk contains much more resin than rubber, and the latter only amounts to about 0.2 per cent of the plant.

The Russian dandelion, kok-saghyz, is similar in general appearance to English dandelions, but contains a much higher proportion of rubber, usually about 10 per cent. Experiments on the cultivation of kok-saghyz are being made in Great Britain, under the general direction of the Royal Botanic Gardens, Kew, as well as in other parts of the Empire and the United States, but it will be difficult, for the time being, to spare in Great Britain the tens of thousands of acres of good agricultural land which would be required to produce 1,000 tons of rubber a year, which is only 1 per cent of our imports prior to 1939.

The rubber-bearing plants of Great Britain are few and insignificant compared with those in other parts of the Empire. According to a report of the Imperial Agricultural Research Institute of India, there are in that country 268 species of plants which are stated to contain rubber. A list of rubber-bearing trees, bushes and plants in Africa, recently prepared by

* Substance of a paper read before the Royal Society of Arts on December 14. 
the Imperial Institute, contained the names of 137 different species. Rubber-bearing plants also occur in Northern Australia, Ceylon and the West Indies. Although it would appear that the Empire is rich in rubber-yielding plants, most of them yield a complex mixture of vegetable substances of which rubber forms only a small percentage. No product contain. ing less than 10 per cent is likely to be of value as a source of rubber, and even this proportion raises difficulties. This is unfortunate, as several plants yield copious supplies of latex, the solid content of which contains between 10 and 20 per cent rubber hydrocarbon. Probably the best known of these plants is the bush Euphorbia tirucalli and other species of Euphorbia in South Africa. One tapper can collect about two gallons of Euphorbia latex a day, which is equivalent to about $6 \mathrm{lb}$. of solids containing, at the most, $1 \mathrm{lb}$. of rubber. The most expensive item in the operating costs of rubber production is tapping and collection, and more than ten times the labour force is required to produce the same weight of rubber hydrocarbon from Euphorbia sp. as from plantations in the East. In addition, the rubber hydrocarbon of Euphorbia is mixed with six or seven times its weight of vegetable resins which make it soft and difficult to vulcanize without purification. The usual method of purification is to extract the resins with a solvent, such as alcohol. The purified rubber is of fair quality, and can be used in association with better rubber for many purposes. The mechanical difficulties of purification are, however, considerable and have not yet been overcome on a large scale.

In view of these difficulties it is probably easier and more economical in man-power and materials to find uses for the unpurified product in directions where the strength and elasticity of rubber are only required to a mild extent. This is the policy which has been pursued in Great Britain in connexion with the utilization of Niger paste, which is the coagulated latex of Carpodinus hirsuta, a vine widely distributed in West Africa. The paste contains little over 10 per cent rubber hydrocarbon, but intensive investigations by a number of organizations have indicated directions in which it can be used without purification, and which will save a corresponding proportion of good rubber for important purposes.

The rubber-bearing plants of importance in the present emergency yield products containing at least 75 per cent hydrocarbon, and some of them between 85 and 90 per cent, which is almost as pure as rubber produced on the Eastern plantations. Reference should be made, however, to a tree, Ficus vogelii, widely distributed in the forests of West Africa, which yields a product containing 50 per cent rubber hydro. carbon. Single trees furnish as much as $10 \mathrm{lb}$. of solids annually. The product is too impure for the more exacting uses of rubber, and, prior to the present emergency, there was no market for it. It can be used, however, in manufactures where a high proportion of rubber is not required.

The source which dominates all others is, of course, Hevea brasiliensis, which is a large tree about $60 \mathrm{ft}$. high, generally grown from seed, and is not ready for tapping until five years after planting. The trees are planted about 100 to the acre, and each mature tree yields about $5 \mathrm{lb}$. of rubber per annum. Some trees yield much more than this, and by grafting the buds of large yielders on to a suitable stock, it has been possible to develop progeny which yield more than 1,000 lb. per acre. The trees are tapped by removing a shaving of bark from a portion of the circum. ference. Immediately the cut is made, rubber milk or latex commences to exude and slowly flows over the cut surface into a cup attached to the tree. Each tapping yields about 3 oz. or more of latex, containing about $1 \mathrm{oz}$. of rubber. One tapper can tap about 300 trees per day, and so obtains about $15 \mathrm{lb}$. of rubber. The latex is transported to the estate factory, where the rubber is separated by adding an acid. The coagulum is then passed through mangles and finally dried either in air or in smoke.

The outstanding advantages of Hevea as a source of rubber are the large yield per acre, the low cost of collection, the low maintenance costs and the ease with which rubber of the best quality is separated from the latex. On the other hand, Hevea takes many years to reach maturity, and each individual. tree then requires the attention of a tapper at intervals of a few days, and it is only because yields are high and labour is cheap that rubber can be produced at about $6 d$. per lb. After the latex has arrived at the factory and can then be handled on a large scale, the cost of manufacture is extremely. small.

In the case of a small plant, such as kok-saghyz, it is possible to envisage a cheap annual crop based on mechanical cultivators, harvesters and mass-production factories. The retail price of beet sugar suggests that dandelion farms, supplying central factories, may be able to produce rubber at $6 d$. per lb. so long as yields are good and the technical side runs smoothly. Yields are not yet good enough in a strictly competitive market, and factory treatment requires further study.

The difficulties involved are illustrated by the fact that guayule, a product of the bush Parthenium argentatum which can be grown and treated like kok-saghyz, has struggled along for twenty years, receiving intense scientific and practical study in California and is still unable to compete with Hevea. Guayule rubber is, however, a much more resinous product than kok-saghyz and the bush is rather difficult to cultivate, so that the slow progress of guayule is not a satisfactory guide to the rate at which developments may be expected in koksaghyz.

A considerable amount of attention is now being devoted to a woody climber, known as Cryptostegia grandifiora, which is a native of Madagascar, 'but grows like a weed in northern Australia, in various parts of India, in Florida and the West Indies. The Americans think so highly of this plant that they have recently arranged to plant 100,000 acres in Haiti. A large area has also been planted in India, and experiments are in progress in Australia. The chief advantage of this plant is that it grows about $6 \mathrm{ft}$. in the first year, forming a stem about 1 in. in diameter, which is then ready for tapping. It can be planted 10,000 to the acre, is not exacting with regard to climate or soil, continues to thrive when cut and produces an abundance of seeds which are very fertile. The rubber is not quite as good as that from Hevea, but contains about 75 per cent hydro. carbon and can be used satisfactorily for practically all purposes. The method of tapping most favoured at the moment is to tie together the ends of, say, 12 shoots, cut off about 1 in., and then immerse them in a small container. A few drops of latex fall from each shoot and there remains behind a small button of rubber on the cut surface, which is subsequently removed. Estimates of yield per acre vary between 
200 and $750 \mathrm{lb}$. per annum, but estimates have a habit of not being reached in practice, and experience at present is very limited.

Other sources of rubber were intensively developed thirty years ago and have only faded into the background because of the economic predominance of Hevea. Some of them are large trees like Hevea, some are vines and others are shrubs. They all yield reasonable amounts of good-quality rubber and are being exploited to-day in so far as labour is available.

The most important of the trees is Funtumia elastica, which is widely distributed in the forests of west and east tropical Africa. Under forest conditions, it is a large tree with a straight trunk and smooth bark and does not branch until it reaches a considerable height. The usual method of tapping is to remove a small vertical channel of bark, the tapper, by means of ladders and slings, climbing to a height sometimes of $60 \mathrm{ft}$. As he descends he makes inclined incisions, joining the main channel, and so forming a herring-bone pattern on the tree. The latex exudes and flows along each of these side-channels and down the main channel into a. small receptacle attached to the tree near its base.

When Hevea is tapped, the cut surface remains vital, and, on removing a fresh shaving a few days later, the latex again flows and the irritation of continuous tapping causes the flow of latex to increase. This is known as wound response. In the case of Funtumia, the lower edge of the cut dries up and suffers from die-back, so that in order to obtain more latex it is necessary to remove a very thick shaving of bark or to tap in an entirely different position. This eventually results in the death of the tree. Ingenious methods have been devised to overcome this difficulty, but they do not appear to be universally successful. Whatever method is employed, the first tapping yields the most latex, after which the yields rapidly decrease, even when an interval of several months elapses between each tapping. The amount of rubber obtained at the first tapping is usually about 4 oz., so that in order to obtain $10 \mathrm{lb}$. of rubber, which is the minimum daily output of a tapper in Malaya, it is necessary for one man to tap forty Funtumia trees. In view of the height to which these trees are tapped, and the fact that one acre of forest may contain only two or three trees, it is impossible for wild Funtumia rubber to compete with plantation Hevea.

In the early days of the rubber-growing industry, it was urged that since Funtumia trees were so widespread in Africa, it was the ideal tree to grow on plantations in that country. The argument had considerable appeal ; but tapping difficulties and the poor yield, with consequently higher costs of collection, were fatal, and most of the plantations were eventually abandoned. Those which have not been destroyed are proving of value in the present emergency, but so far the problem of economic production remains unsolved, and there is no indication that after the War the exploitation of these trees will be continued. The rubber is of excellent quality, but not quite so good as Hevea rubber.

Another tree which attracted much attention in the early days is Manihot glaziovii, more popularly known as ceara. It is a smaller tree than Hevea and can be planted more densely. Whereas Hevea plantations usually have 100 trees or less per acre, ceara plantations have about 300 . The tree is also less exacting with regard to climate and soil. This suggested to the early planters that the ceara tree might be grown in localities where the conditions were not favourable to Hevea, particularly in parts of Ceylon and in East Africa. The tree grows very quickly from seed, and can be tapped after two years. This is of great interest in the present emergency, in which the development of quick sources of rubber is of strategic importance. It is only fair to point out, however, that no authoritative information is available about the yields of young ceara or about the quality of the rubber. The tapping of young trees with thin bark, small surface and poor yields presents considerable difficulty and has not been studied as a commercial proposition.

Even the mature ceara tree is not easy to tap, and the yields are so low in the dry areas that insufficient latex exudes to overflow into a receptacle. A higher yield is obtained in the more humid areas, but an annital yield of $200 \mathrm{lb}$. per acre, containing 300 trees, is above the average and compares unfavourably with Hevea. Very high yields are recorded for individual ceara trees-as much as $10 \mathrm{lb}$. per annum. This corresponds to 3,000 lb. per acre, if it is possible to develop reliable, high-yielding offspring, but the low yield is not the only factor operating against future development. The ceara tree does not stand up well to tapping, particularly in the dry areas. So late as 1914 it was reported from Ceylon that no method of tapping the tree was known which did not cause death. In addition, the bark of the ceara tree has a hard outside layer, which quickly blunts the tapping knives, and which also tends to separate from the inside layer which contains the rubber-bearing vessels. It is usual, therefore, first to remove the outside layer from the area which has to be tapped, and then to employ a conservative system of tapping so as not to injure the tree.

There are a number of abandoned ceara plantations, particularly in East Africa, which have now been reopened, but prospects after the War do not appear promising.

The most important indigenous sources of rubber in Africa are the numerous woody large vines, widely distributed in the tropical forests. The principal genera are Landolphia, Clitandra and Carpodinus, containing numerous species. The best sources of rubber are confined to four or five species of Landolphia in West Africa and a similar number in East Africa, together with a little Clitandra and Carpodinus. The vine rubber from these sources is of excellent quality, that from the Landolphia spp. containing about 90 per cent hydrocarbon in West Africa and 85 per cent in East Africa.

In the rubber boom of 1910 , when the total output from all sources in Africa reached 20,000 tons, vines were recklessly tapped and, in many cases, completely destroyed. A vine requires about ten years to grow from seed and about five years to grow again when partially cut down, so that the damage done during the rubber boom is by now largely repaired; but the balancing of productive capacity against probable useful life is still important, partiaularly as there is a risk of obtaining much rubber at first and none during the rest of the war period.

A usual method of tapping is to eut the bark at intervals, and climbing among its twisted branches for the purpose is regarded as hard and dangerous work. The yield is $1-8 \mathrm{oz}$. of rubber per vine, and 
after several months, when the cuts have healed, the treatment can be repeated. An area of forest containing two vines per acre is regarded as a rich source of rubber, so that $1 \mathrm{lb}$. of rubber per acre is an excellent yield. A cautious tapping treatment would probably have little effect on the life of the vine; but the tendency is to get as much rubber as possible with the least effort, so that it will not be surprising if the yield of vine rubber reaches a peak and then diminishes as the sources of supply are destroyed.

In normal circumstances vine rubber cannot hope to compete with plantation rubber produced in the Far East, chiefly because the harvesting of the rubber involves the same type of operations with much smaller yields and more difficult conditions. This comment does not apply, however, to some species of Landolphia, etc., particularly Landolphia thollonii, which, growing in poor soil in open country, does not develop into a climbing plant, but throws out long underground stems ramifying in all directions, with small tufts of foliage above ground at irregular intervals. The bark of these stems contains about 15 per cent rubber and in some areas, particularly in French Equatorial Africa, there is such a mat of stems that every footstep covers a treasure of buried rubber, The stems have been known to reach sixty yards in length, and as they are only a few inches below the surface they are not difficult to gather and cut off near the tap root. They are then dried a little to coagulate the latex, cut into convenient lengths and smashed with a mallet so as to facilitate the removal of bark. Finally comes the laborious opera. tion of pounding the bark, so as to convert it into a powder and mass the rubber together into small lumps. It is estimated that 15 hours beating is required to produce $1 \mathrm{lb}$. of rubber. Since the supply of labour is limited, such a process cries out for mechanization. One method is to run the bark for some time through heavy grooved mangles, that is, ordinary rubber washing machines; but these machines are difficult to obtain under present conditions, and there is only a small output for a given input. A study of the problem in Great Britain and in South Africa suggests that the most suitable type of grinding machine is a rod mill, consisting of a revolving cylinder containing loose rods which rise and fall and rotate as the cylinder revolves. The mechanical method is essential to the success of several of the new sources of rubber, such as the Russian dandelion, root rubber, the bark of vine rubber from which the latex does not flow freely and even for bark shavings obtained on plantations in Ceylon, which were often thrown away because they contained only 5 per cent rubber. On a large scale it should be a fairly cheap method of obtaining rubber, particularly if a continuous process can be devised.

A survey of competitive rubber plants would not be complete without a reference to Castilloa and Ficus elastica. Both have been cultivated on a small scale in different parts of the Empire, but on account of small yields, and for other reasons, cannot hope to compete with Hevea after the War. The whole trend of this paper shows that trees which have to go through the same cyele of operations as Hevea in order to obtain rubber are hopelessly outclassed by the latter with regard to yield, quality and ease of treatment. Small plants may be more successful, however, because their cultivation and treatment can be mechanized, and operations can be based on an annual instead of a daily cycle.

\section{OBITUARIES}

\author{
Prof. W. W. C. Topley, F.R.S.
}

William Whiteman Carlton Topley was born in 1887. He was educated at the City of London School, St. John's College, Cambridge, where he obtained a first class in the Natural Sciences Tripos, and St. Thomas's Hospital, London, and qualified in medicine in 1909. In 1910 he was appointed director of the Pathological Department at Charing Cross Hospital, and started a private practice in Harley Street.

In 1914 he accompanied Colonel Hunter to Serbia, where an epidemic of typhus was raging. There is little doubt that his sensitive nature was stirred by the tragedies he saw in a community affected by infectious disease, and that this experience decided his main line of research, namely, an experimental study of the factors involved in the spread of epidemic disease. He returned to England in 1916 and rearranged his life so that he could devote himself entirely to research and teaching. He quickly set to work and showed from the very outset how hard and fast he could work, a characteristic which has staggered all those who have followed his activities.

In 1919 Topley's researches were attracting much attention, and he made a preliminary report of them in the Goulstonian Lectures. In 1922 he accepted the chair of bacteriology at Manchester, and for five years rigidly limited his interests; with a small group working devotedly around him he studied the spread of epidemic disease in mice.

In 1927 he became professor of bacteriology and epidemiology at the London School of Hygiene. Here, in association with Greenwood and other colleagues, he carried on his researches, the results of which and the views which emanated from them he wrote up in his clear, forceful and interesting style. He delivered the Milroy and Harben Lectures, and in 1930 the importance of his work was recognized by his election to the Royal Society. In addition, he threw great energy into the academic diploma course of bacteriology which he had started, and wrote with G. S. Wilson a large text-book of bacteriology. $\mathrm{He}$ began, moreover, to take an interest in committee work, and allowed his scientific interests to develop more widely by seeking contacts with scientific men working in other branches of biological research.

In a very short time Topley was serving on the Council of the Royal College of Physicians, the Council of the Royal Society, the Medical Research Council, and the Animal Diseases Committee of the Agricultural Research Council. His book had been an outstanding success ; and scientific workers from every side were asking for his time, help and advice. He responded to these added burdens by increasing the tempo of his work and thought, by working harder, and by arranging and rearranging his mode of life so as to attain maximum efficiency.

In 1939, certain that war was coming, Topley was determined to prevent, if possible, the tragedy of infectious disease spreading through the community. Largely due to his efforts, the Emergency Public Health Laboratory Service was set up in Great Britain to combat this danger. At the same time he gave his help to a group of pathologists who, as a result of the experiences of air-raiding in the Spanish War, were pressing for an effective blood transfusion service for the London area, and the London Emergency Blood Supply Depots came into being. As 